Historic, Archive Document

Do not assume content reflects current scientific knowledge, policies, or practices. 



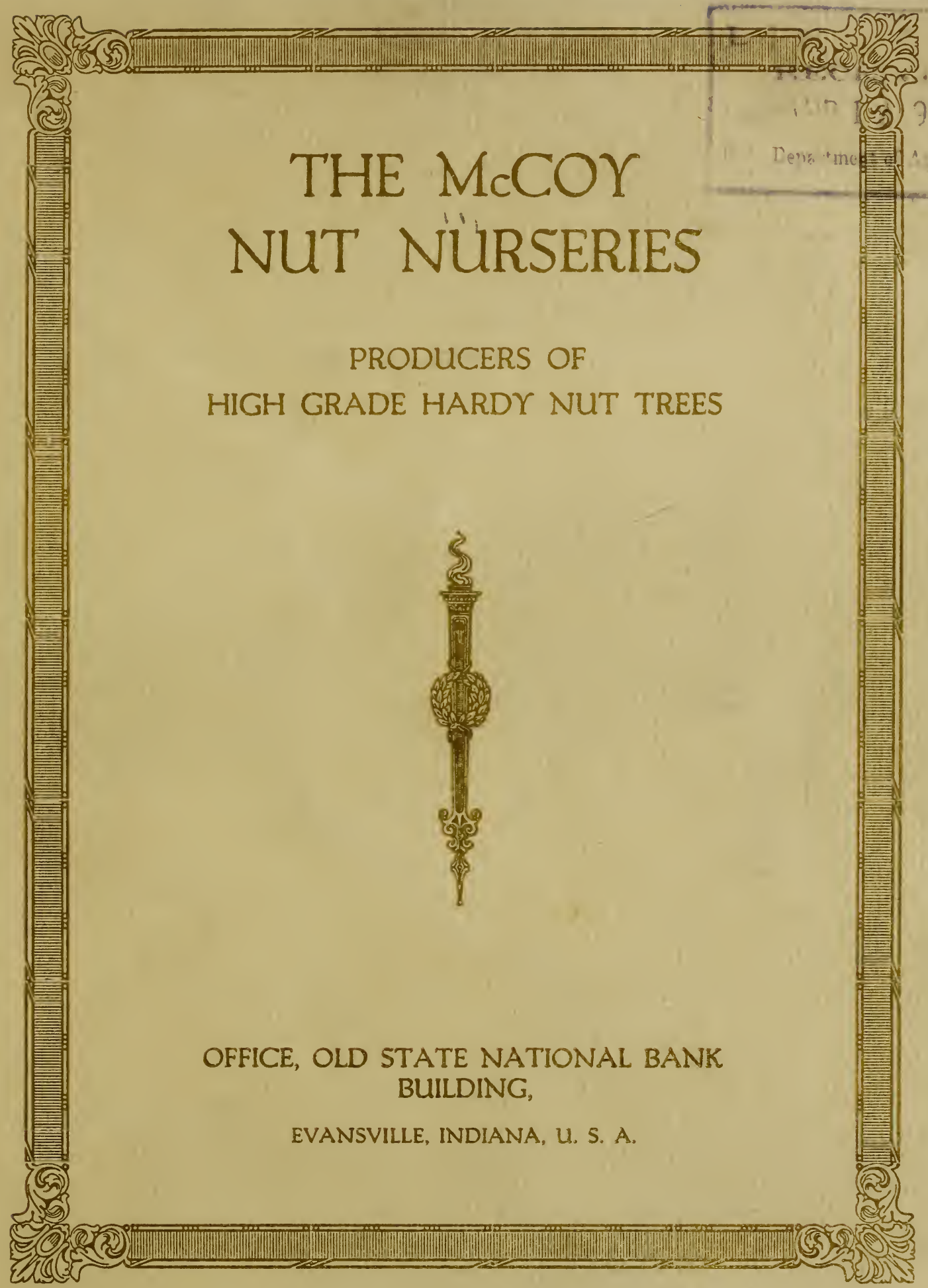





\section{THE McCOY NUT NURSERIES}

SUCCESSOR TO OHIO VALLEY FOREST NURSERIES

\section{GROWERS OF HIGH GRADE HARDY NUT TREES}

PRODUCERS OF NEW VARIETIES OPERATING THE LARGEST HARDY NUT TREE NURSERIES IN AMERICA

NURSERIES IN SPENCER COUNTY, INDIANA, OFFICE, OLD STATE NATIONAL BANK BUILDING, EVANSVILLE, INDIANA, U. S. A. LONG DISTANCE TELEPHONE 935 


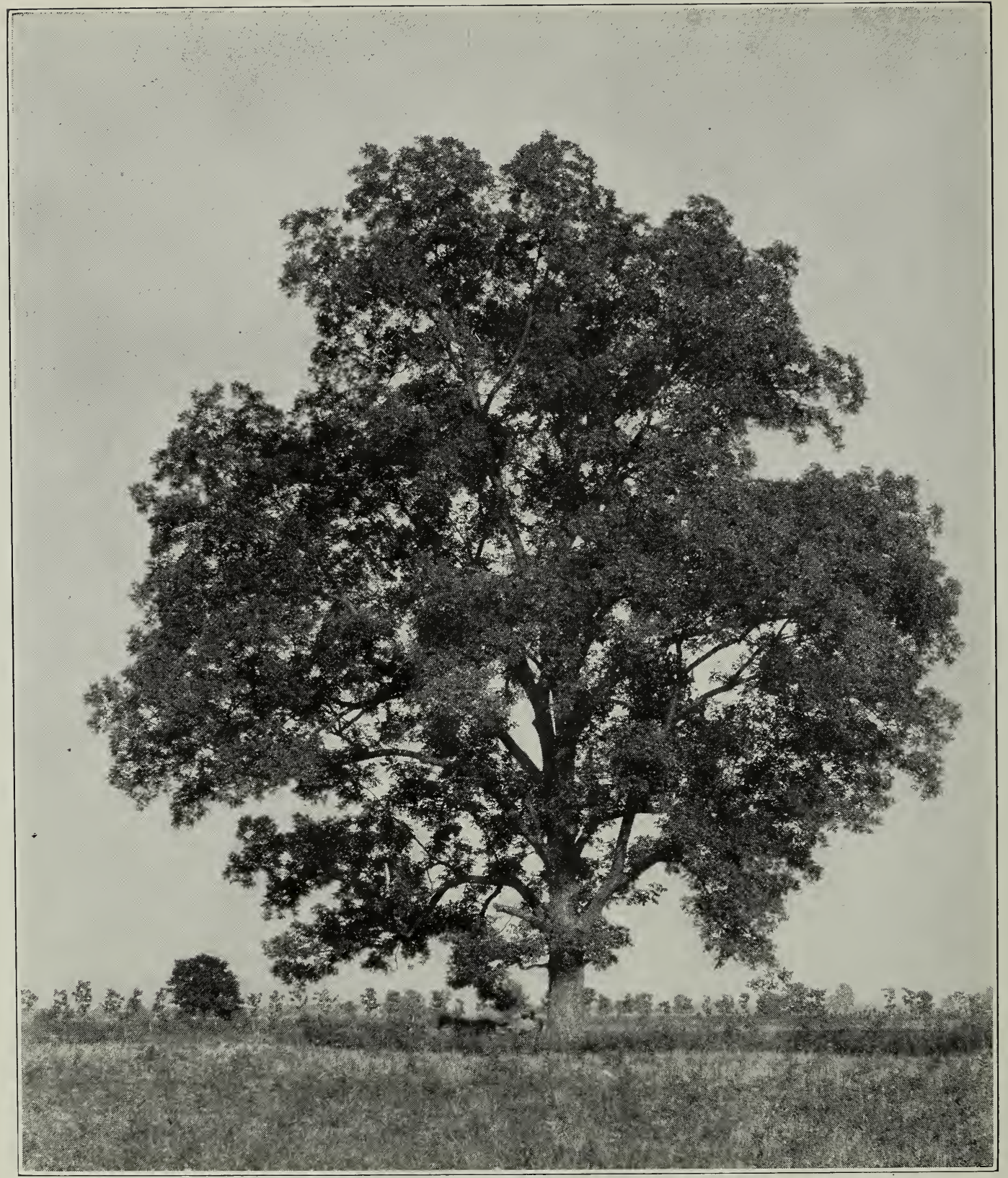

THE FAMOUS BUTTERICK PECAN TREE, KNOWN TO HAVE BEEN BEARING FOR OVER 117 YEARS. 


\section{FOREWORD.}

The demand for information upon Hardy nut trees and as to where they may be successfully grown, has become so intense that in presenting this catalogue for your consideration, we have endeavored to give accurate descriptions with illustrations of most of the varieties. The cuts of the nuts herein contained are true to life.

It is also our desire to show those who are not yet informed, the immense profit in Hardy nut trees. In many cases the returns are so stupendous that a person not familiar with the actual conditions, will be inclined to disbelieve many of the statements.

Away back in 1878 Robert L. McCoy, then a young lad, exhibited a great interest in trees. Mr. McCoy was born in Luce Township, Spencer County, Indiana, a township famed far and wide for its land, which is probably unsurpassed for richness and fertility in the entire United States. From the year 1878, Mr. McCoy has been a constant student of nature, and as a child planted hundreds of Hickory and Pecan trees upon his father's farms and in early life he knew the botanical names of all the hickories and similar trees, of which family the Pecan is a member.

Mr. McCoy has devoted practically his entire life, and all of his mature years to the propagation of fruit and nut trees, especially the latter, and probably there are no propagated varieties of nuts in America with which $\mathrm{Mr}$. McCoy is not familiar.

The Hardy Pecan is a native of the valleys surrounding Evansville, Indiana, and within a radius of one hundred miles of this city and before Mr. McCoy was seventeen years of age, he had ransacked the valleys of the Ohio, Wabash and Green rivers and their tributaries for different varieties of Pecans, and in his youthful enthusiasm he was much more thorough than probably any other man in America, and to his intense and eager study and his untiring energy is noted the fact that at least four of the leading Pecans now extensively advertised and sold by all Hardy Pecan Nurseries, were discovered, introduced and named by our Mr. McCoy.

The nut world gives to Mr. McCoy the credit of being one, if not the leading authority on Hardy Pecans and their culture.

In $1908 \mathrm{Mr}$. McCoy established our present Nursery under the name of Ohio Valley Forest Nurseries, in Luce Township, Spencer County, Indiana, and began in earnest the propagation of high-grade nut trees. Being a pioneer in the business, he suffered many mishaps and failures and thousands of experiments were made which resulted only in expense and experience. But through these failures the light came and the years of failures and experiments have produced for the McCoy Nut Nurseries, a man whom we consider has very few if any equals, and certainly no superiors in his life work, in America.

THE MCCOY NUT NURSERIES. 


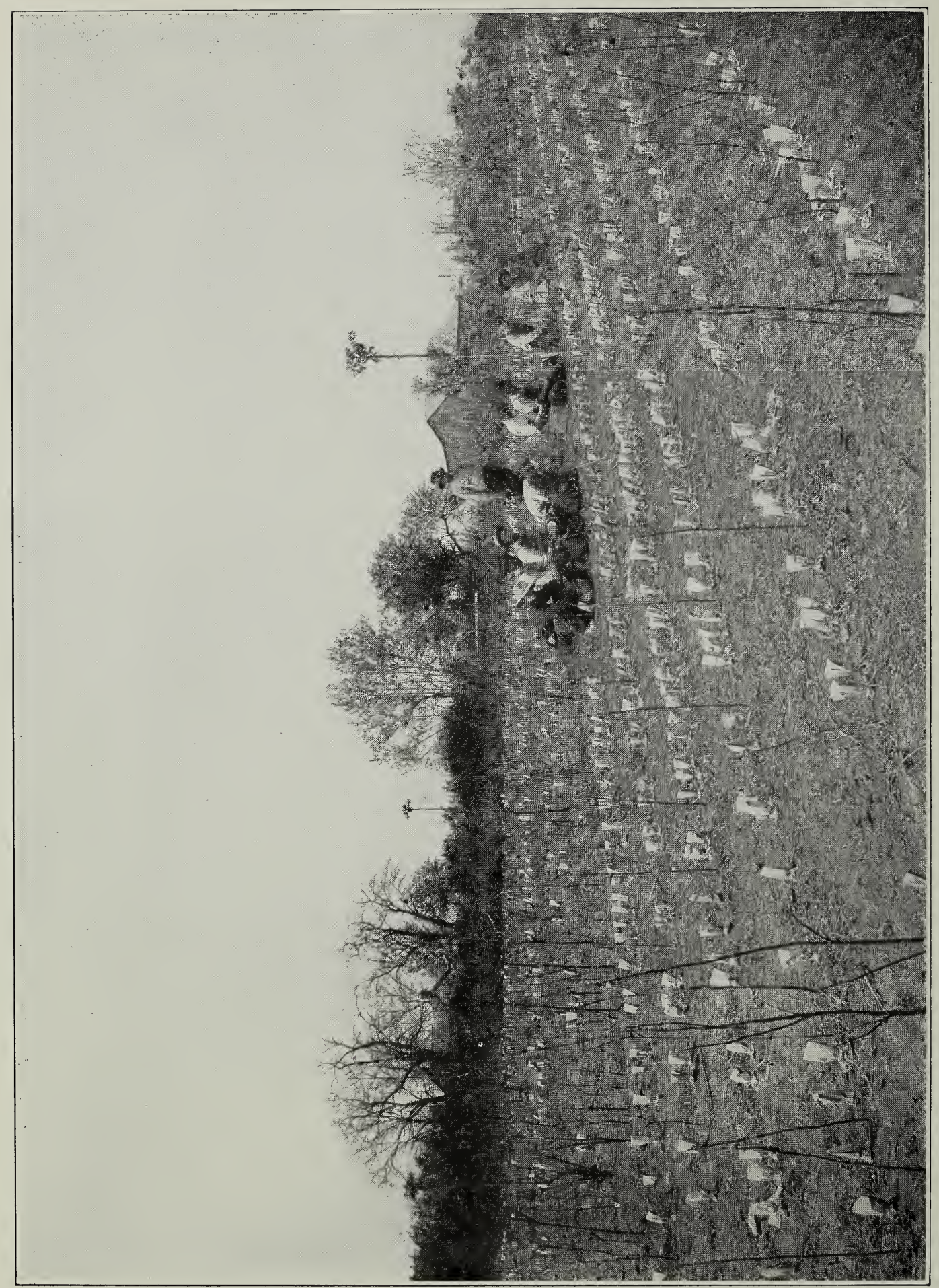

ป 


\section{INTRODUCTION.}

The McCoy Nut Nurseries offer this catalogue guaranteeing that they are presenting to the public the best that can be produced by the very latest and most scientific methods of propagation, combined with the closest personal supervision of R. L. McCoy.

The McCoy Nut Nurseries make a specialty of the highest grade, budded and grafted hardy nut trees, especially the Pecan, Chestnut, Almond, English Walnut, Hickory and Chinquapin.

Our Nurseries and office are located in the heart of "The Evansville District," which district embraces a territory within a radius of one hundred miles of Evansville, and in which territory are located all the Mother Trees of the Hardy, Northern Pecan, so that our office and Nurseries are in the center of this district, from which point all the magnificent old Mother Trees from which we procure our stock, are easily accessible.

Many of the laws of nature are the same in plant life as in animal life and the old statement that "blood will tell" is just as applicable to plant as to animal life, in fact many horticulturists hold that it is more applicable in the former case.

However that may be, it is a well known fact that seedling nut trees do not come true to variety but may come true to type, and in order to obtain exactly the same nut as the Mother Tree produces, it is necsssary for the seedling to be either budded or grafted with scions from the parent tree.

It is a fact that only about $60 \%$ of seedling Pecan trees ever come into bearing at all and the average age at which seedlings come into bearing is about twenty years. Budded and grafted Pecan trees of ten bear in the nursery row at two or three years of age, but the transplanting of them naturally sets them back and it is our observation that budded and grafted Pecan orchards come into bearing at about the age of apple orchards, that is from three to seven years.

The budding or grafting of our wild native nut trees increases their size about one-fifth and also increases their productivity. Budded and grafted nut trees come absolutely true to variety so that the planter may know in advance just what kind of nuts his trees will produce and also that every budded and grafted Pecan tree will produce fruit. This idea of pedigreed stock is only lately being given the great importance it demands and "thinkers" and "doers" in the horticultural world are demanding the budded or grafted stock.

We therefore desire to call special attention to the fact that every Pecan tree listed for sale in this catalogue is guaranteed absolutely true to name; that the seedling has been grafted or budded with the scions taken from the old Moth- 
er Tree. These scions or bud wood were not bought by us from people who claim that they came from the old Mother tree, but were cut, and immediately tied up in bundles and tagged by our Mr. McCoy and afterwards grafted or budded on to the stock which we offer you, by our employees and in our own Nurseries, each piece in such a manner and with such a system that the chance for a mistake is infinitesimal. We therefore again desire to impress upon the prospective purchaser that any Pecan tree bought from us is guaranteed to be just what we say it is. We can further say that it is through us, and only us, that the bud wood from seven of these old Mother Trees was originally distributed to the members of the Northern Nut Growers Association.

In regard to our Chestnut, Chinquapin, English Walnut and other nut trees, we can say that we also guarantee this stock to be absolutely true to name and grafted or budded with scions that were from the old bearing, Mother Trees, the greatest portion of which we have fruited in our Nurseries, and we issue the same guarantee for these that we do for our Pecan trees.

Instead of planting maple, poplar, etc., for shade, why not plant our Hardy nut trees? Thereby having not only a splendid shade but producing delicious and nutritious nuts as well, which may be enjoyed by you and your posterity for years to come. 


\section{TO PATRONS.}

\section{CORRESPONDENCE.}

Address all communications to our office in the Old State National Bank Building, Evansville, Indiana, where they will receive prompt and intelligent attention.

\section{PLANTING.}

We gladly give all information required for the planting of any tree found listed in our catalogue, and desire to suggest that the profits in large nut orchards are immense. Not only this, but it is astonishing what profits can be obtained from the crops of one, two or three trees planted upon the lawn. For large plantings, we send an expert to look the place over, to recommend the location of the trees and to supervise the actual planting thereof.

\section{PRICES.}

The prices quoted in our price list, unless otherwise stated, are f. o. b. our Nurseries. We make no charges for packing or boxing and all goods are delivered at freight and express of fices free of charge.

\section{DIRECTIONS FOR SHIPPING.}

In ordering goods please state whether by freight or express. Nursery stock is carried by the express companies at about $20 \%$ less than regular merchandise. We prefer to ship by express and will do so unless instructed otherwise. Freight shipments go at risk of purchaser.

\section{TERMS.}

Cash on or before delivery to transportation companies, excepting where we open accounts with patrons by previous arrangement.

\section{OUR RESPONSIBILITY.}

We refer you to the Old State National Bank of Evansville, Indiana, or any mercantile agency.

\section{GUARANTY.}

We guarantee every tree listed in this catalogue as fresh stock when shipped and absolutely true to name. When shown to our satisfaction that any nut tree sold by us is untrue to name or otherwise not as represented, we not only cheerfully agree to replace same, but insist that we be allowed to do so.

\section{SEASON FOR PLANTING.}

Opens about November first and closes about May first.

\section{HOW TO CARE FOR STOCK WHEN RECEIVED.}

Soak the trees with water, and either place them in a cellar and keep wet, or bury them in a trench until the holes are ready for transplanting. If at all dry and shriveled, the best plan is to bury them, root and branch in wet earth. If frozen, they should be buried in earth until the frost is removed. Do not expose the tender roots to the sun or weather. 


\section{PECANS.}

Pecans will do well on almost any soil and can be grown successfully on land containing underlying rock, provided the rock does not come within eight or ten feet of the surface.

The Pecan trees grown in bottom land will produce, generally speaking, more wood and foliage than if grown on upland; but the crop of nuts upon the trees in the upland will be slightly in excess of that produced upon trees in the low land.

Overflow does not seem to affect the trees, in fact in many cases they have appeared to be benefited thereby. For the best results we suggest from eighteen to twenty-five trees to an acre on upland and from sixteen to twenty-two on lowland.

The trees should be planted only when the sap is dormant and the best results are obtained when trees are planted from about the 1st of December to the 1st of February, according to the latitude, which time we will be glad to advise if requested.

Our Nurseries are located in the rich lands of the celebrated Spencer County, Indiana, just a short distance from Evansville, Indiana, and because of the local extremes in temperature, trees propagated in our Nurseries are well able to withstand extremes of both heat and cold.

While our Nurseries produce the very highest grades of English Walnut and Chestnut and other nut trees, we take extraordinary pride in our large $\mathrm{Pe}-$ can Nursery. This Pecan Nursery contains more budded and grafted, northern, Hardy Pecan trees than do all the other combined Nurseries in America.

The Pecan originated as a sport from the Hickory and is of two general varieties; the one native to the southern part of the United States, and the Hardy Pecan, which is probably a native of the territory within a radius of one hundred miles of Evansville, Indiana.

The Pecans grown in the south, so extensively advertised by all southern nurserymen, and we regret to say, by some northern nurserymen, will positively fail when transplanted north of about the 35 th parallel, which is approximately the southern boundary of Tennessee, and we caution prospective purchasers of Pecan trees to be grown north of that latitude, to be sure to obtain the Hardy varieties grown in what is commonly known to nut experts as "The Evansville District."

In addition to this, the Hardy varieties, while in some cases smaller than the southern Pecan, are more nutritious, richer in quality and sweeter in flavor. 
The Hardy varieties will produce satisfactory results in the southland, but it is north of the 35 th and south of the 45 th parallels where they are at their best. In fact, there are some hardy Pecan trees in central Michigan and Canada that are giving most excellent and satisfactory results.

The celebrated Wabash, Green and Ohio river valleys with their hot summers changing speedily to cold weather, is the native home of the Hardy $\mathrm{Pe}-$ can, and these rapid changes from heat to cold, have seemed to harden the tree so that it will stand any kind of weather.

It was at one time believed that the Pecan would succeed only in the river bottoms, but this idea has become obsolete and many fine groves are now on hills and uplands and are producing enormous crops.

The following varieties, among the many tested in our Nurseries, are the only Hardy northern Pecans which we recommend to prospective purchasers. We have eliminated from our list several heretofore well known varieties, as our investigations prove that they are inferior to the varieties herein named.

All these trees are positively guaranteed true to name and our written guarantee accompanies each shipment.
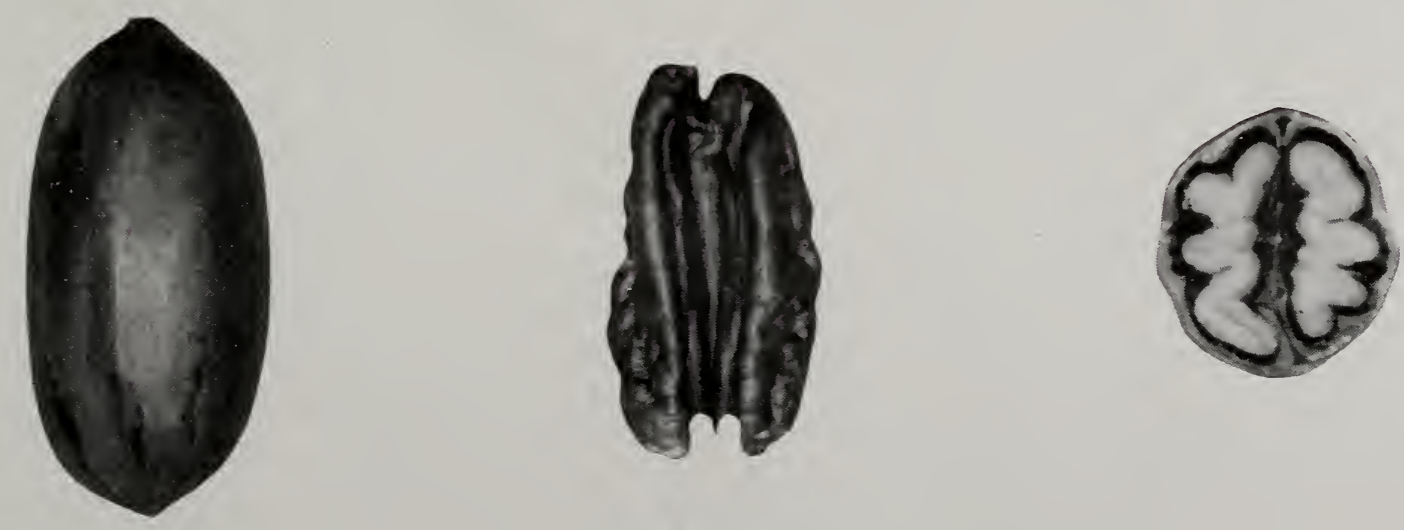

\section{BUSSERON.}

Parent tree, Knox County, Indiana, nut medium size, especially promising for northern range. Thin shell. Kernel very sweet and rich. 

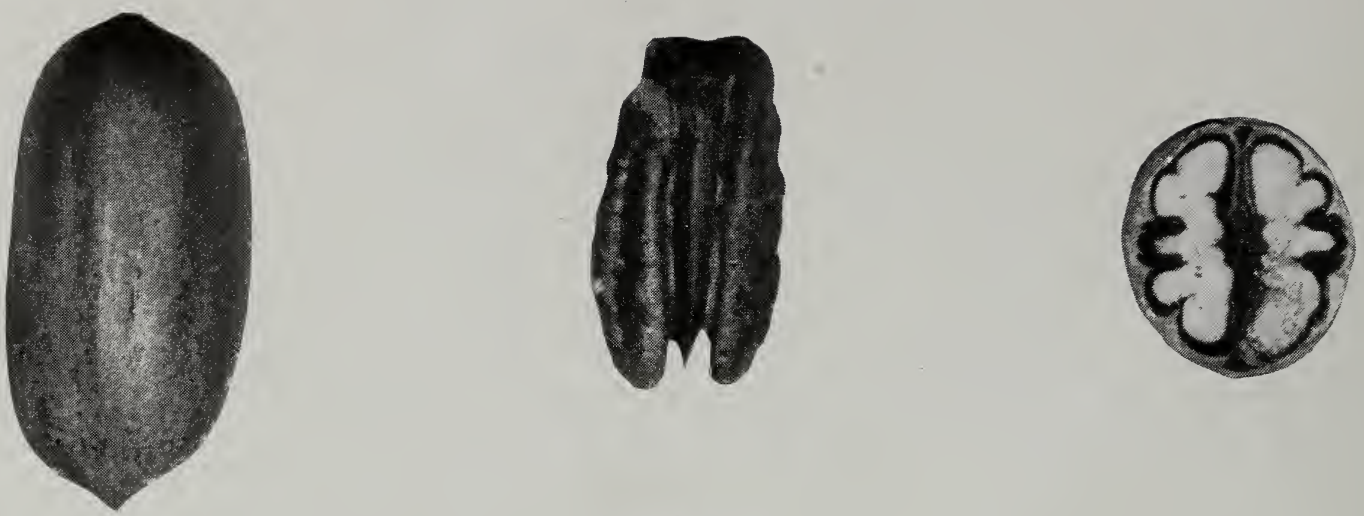

\section{INDIANA.}

Parent tree, Knox County, Indiana. Highly promising for planting in northern range. Size of nut medium, shell of average thickness, quality good, very prolific. Parent tree 1914 crop, 300 pounds.
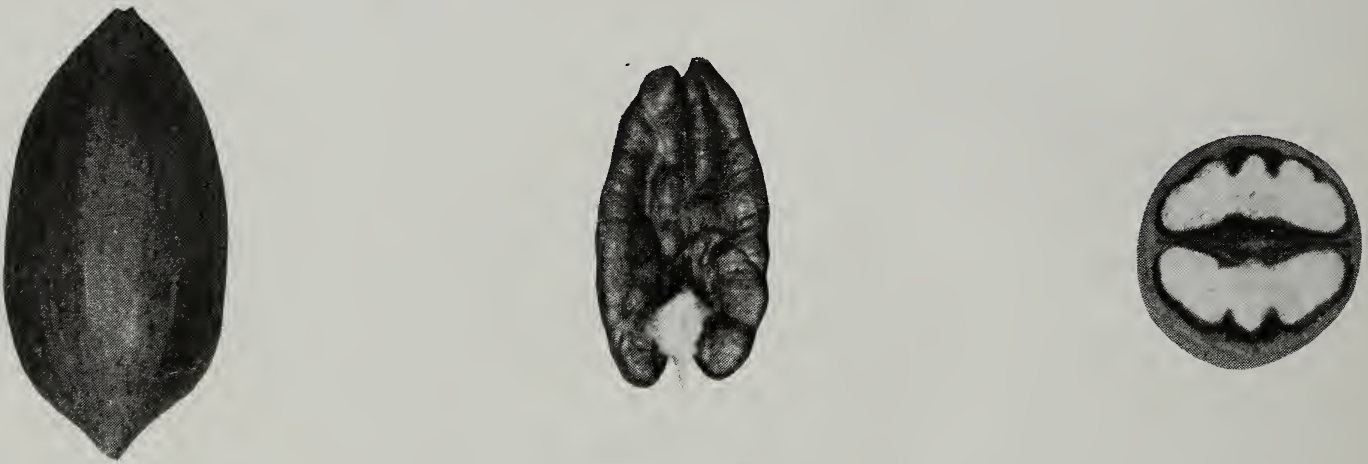

\section{NIBLACK.}

From Knox County, Indiana. Size of nut slightly below medium, shell thin and an excellent cracker, flavor excellent.
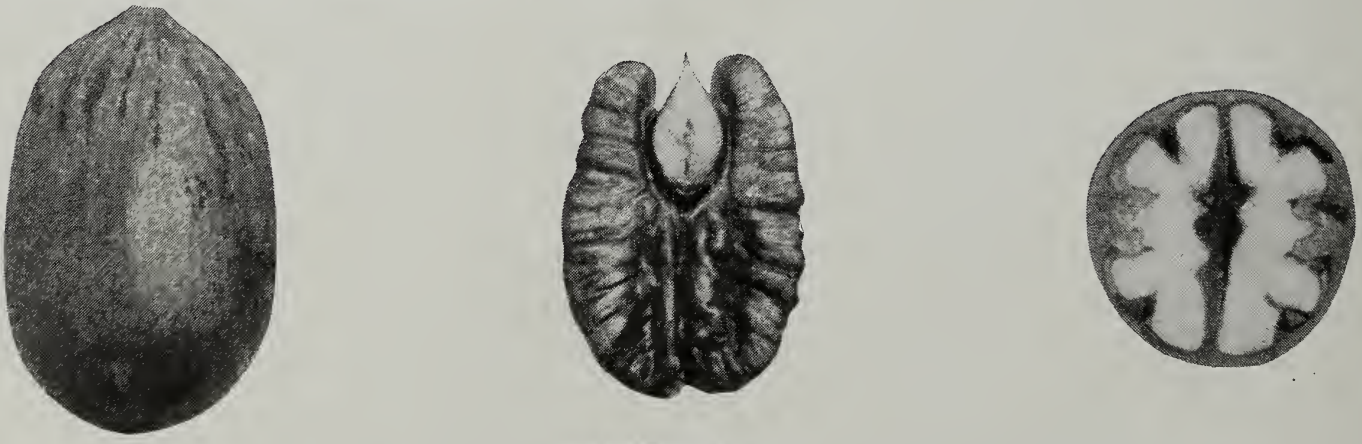

\section{BUTTERICK.}

Large, northern Pecan, shell medium, quality excellent, flavor sweet and rich. Parent tree shown in this catalogue has record of over one hundred years of prolific bearing. Discovered, introduced and named by our Mr. McCoy in 1909. 

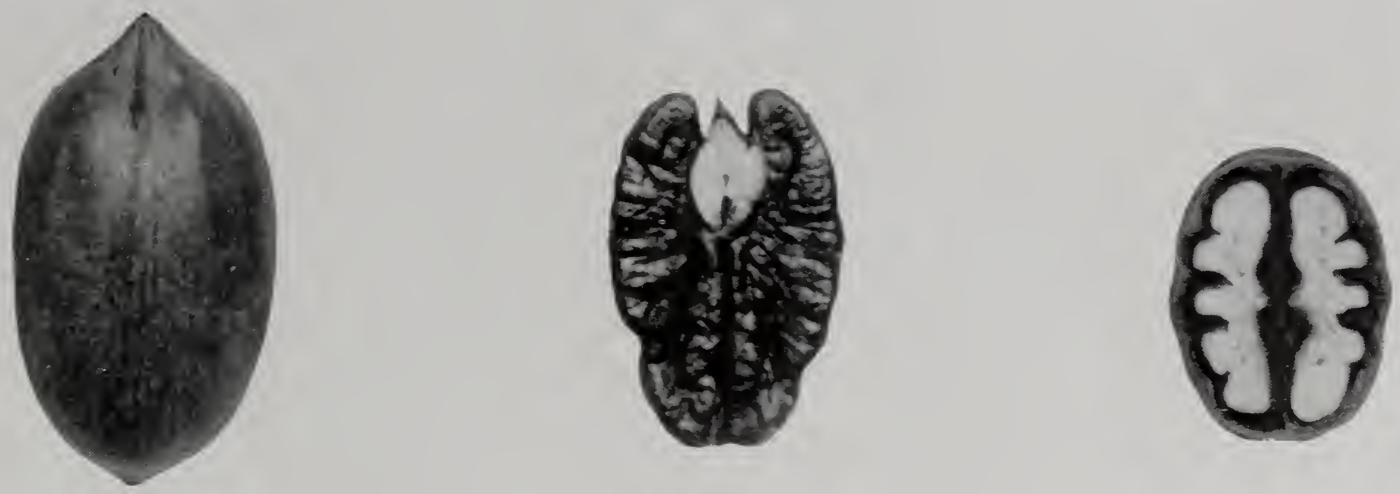

\section{POSEY.}

From Gibson County, Indiana. Largest of the northern nuts, thin shell, excellent cracker, flavor rich and sweet. Discovered, introduced and named by our Mr. McCoy.
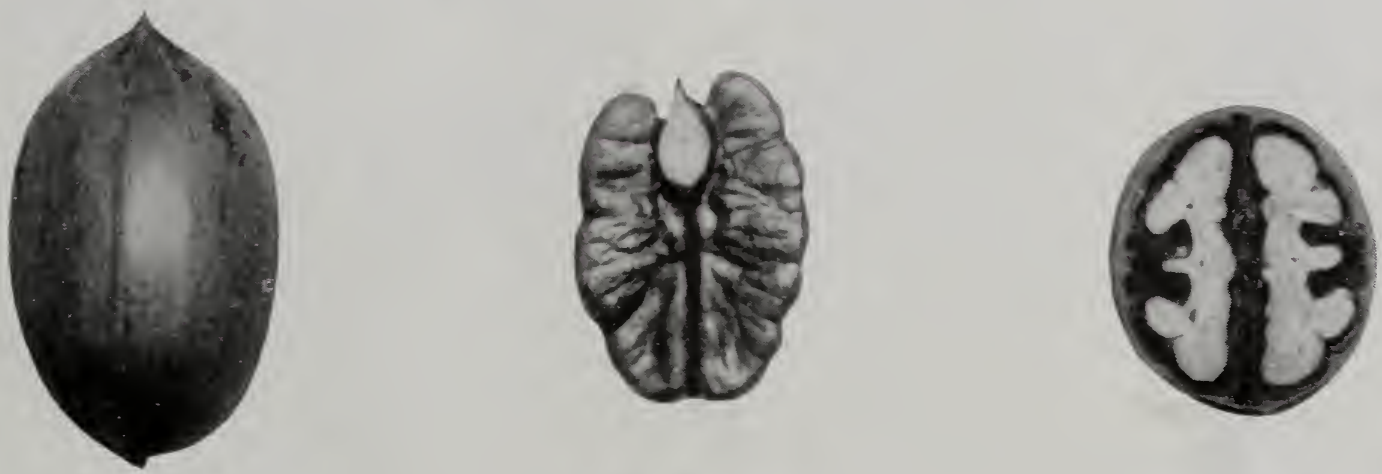

\section{GREEN RIVER.}

Parent tree, Henderson County, Kentucky, size of nut medium, excellent cracker, quality rich, flavor excellent. Named by Mr. Littlepage and our Mr. $\mathrm{McCoy}$.
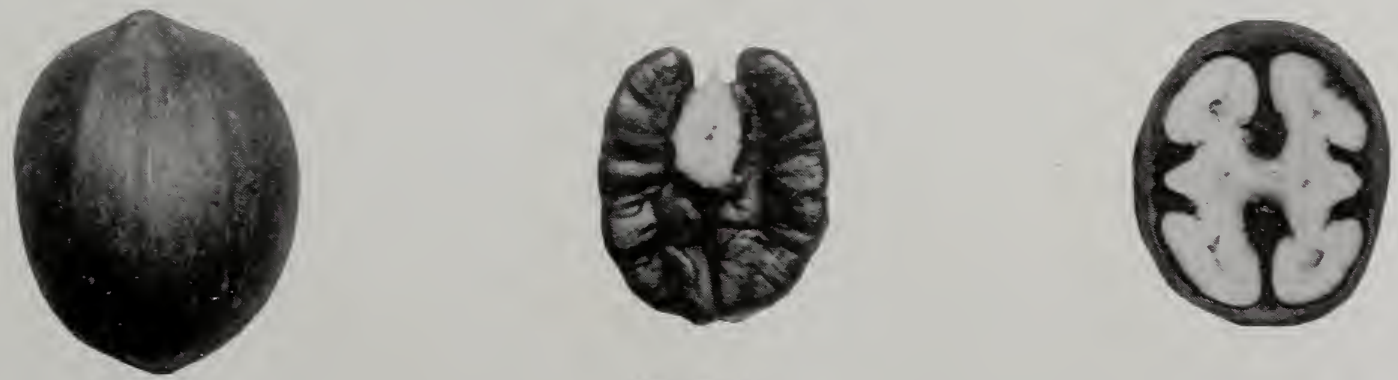

\section{MAJOR.}

Parent tree from Henderson County, Kentucky. Size of nut slightly below medium, shell thin, kernel unusually plump, flavor and quality good, very productive. 

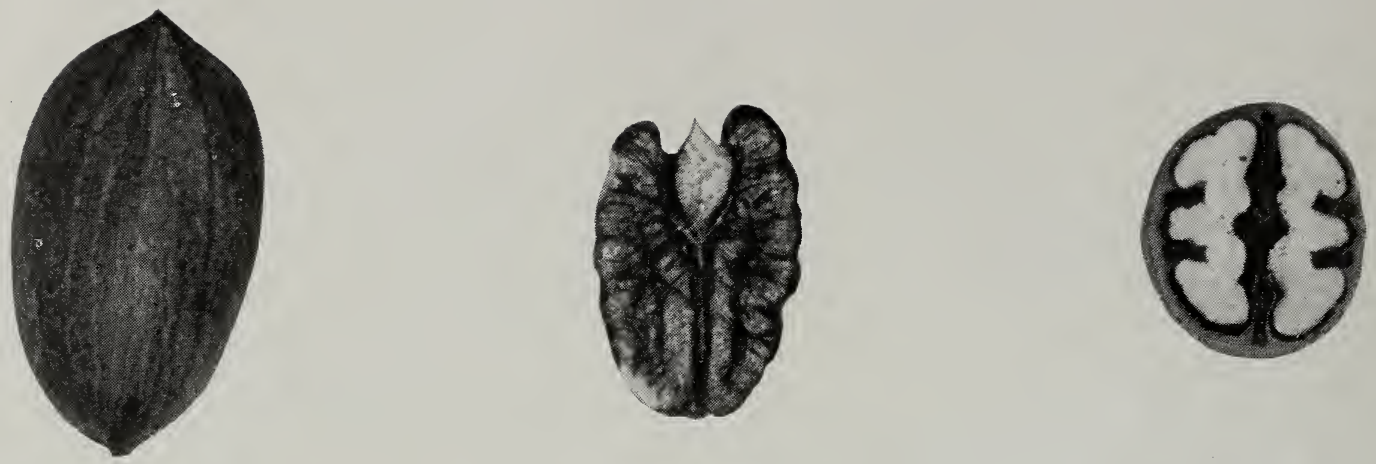

\section{WARRICK.}

From Warrick County, Indiana, size of nut medium, shell moderately thin. Quality rich, flavor excellent. Parent tree very prolific. Discovered, introduced and named by our Mr. McCoy.
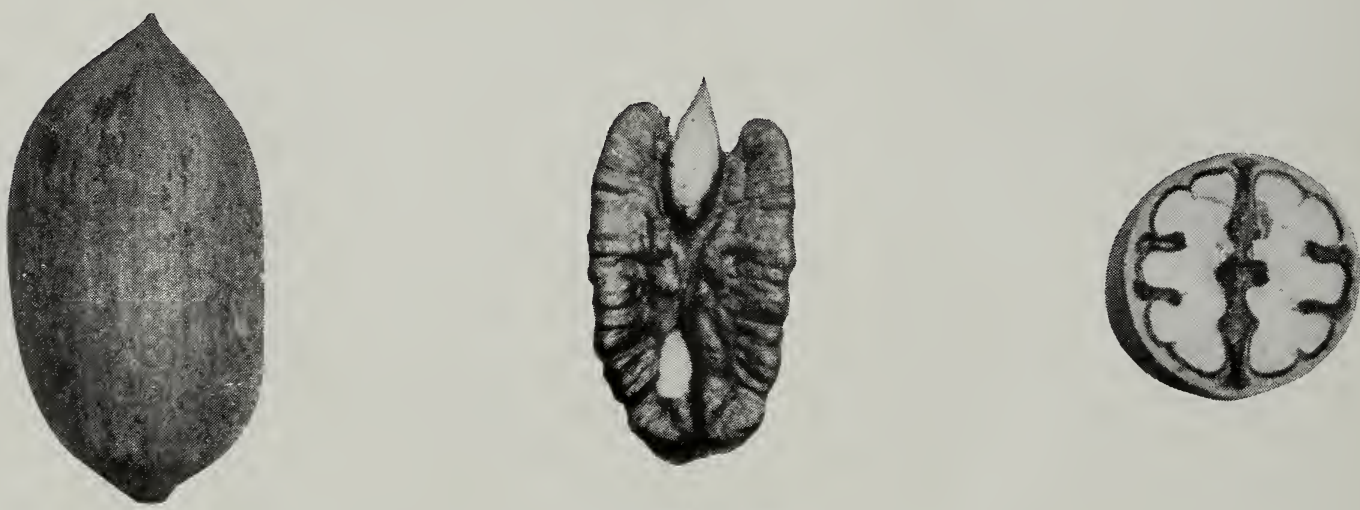

\section{KENTUCKY.}

Parent tree near our Nurseries. Size of nut medium, thin shell, quality excellent, good cracker, parent tree very prolific. Discovered, introduced and named by our Mr. McCoy.

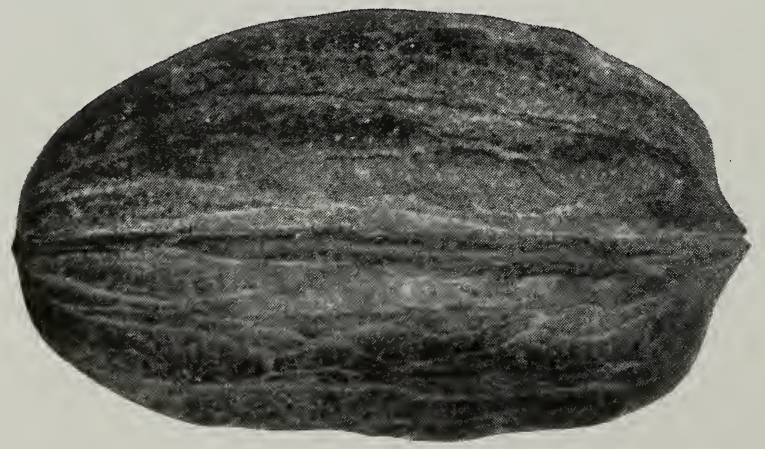

\section{MCALLISTER.}

It is in truth a hybrid, having quite a little hickory blood. It resembles in appearance the $\mathrm{Pe}-$ can, as does the foliage, excepting the terminal bud in winter. 
The old Mother Tree, located in Posey County, Indiana, in pioneer days filled its nut well and bore abundant crops; but in recent years it has not filled well owing to the extreme size of the nut, it being the largest Pecan known. however for the last several years it has filled its nuts

We recommend to Pecan planters that they plant one or two of these trees. as an experiment. Without doubt, it is a hickon or hybrid, but the Pecan characteristics predominate and the tree is an extremely rapid grower. The nuts being of such tremendous size will be a curiosity.

The demand for Pecans for the table far exceeds the supply. Nuts contain more real nutriment than does meat and are rapidly displacing meat in many homes. To those of you whose ground is only a small back yard, plant a Pecan tree and let it shade you as well as feed you. To you who own an acre or more of ground, plant about twenty Pecan trees to the acre, use your land between the trees for other purposes while the trees are growing. Your trees will begin to produce in about four years and before long you will be realizing from $\$ 100.00$ to $\$ 300.00$ per acre from your trees. They will continue to increase their production and will give a larger profit to your children's children than they did to you. 


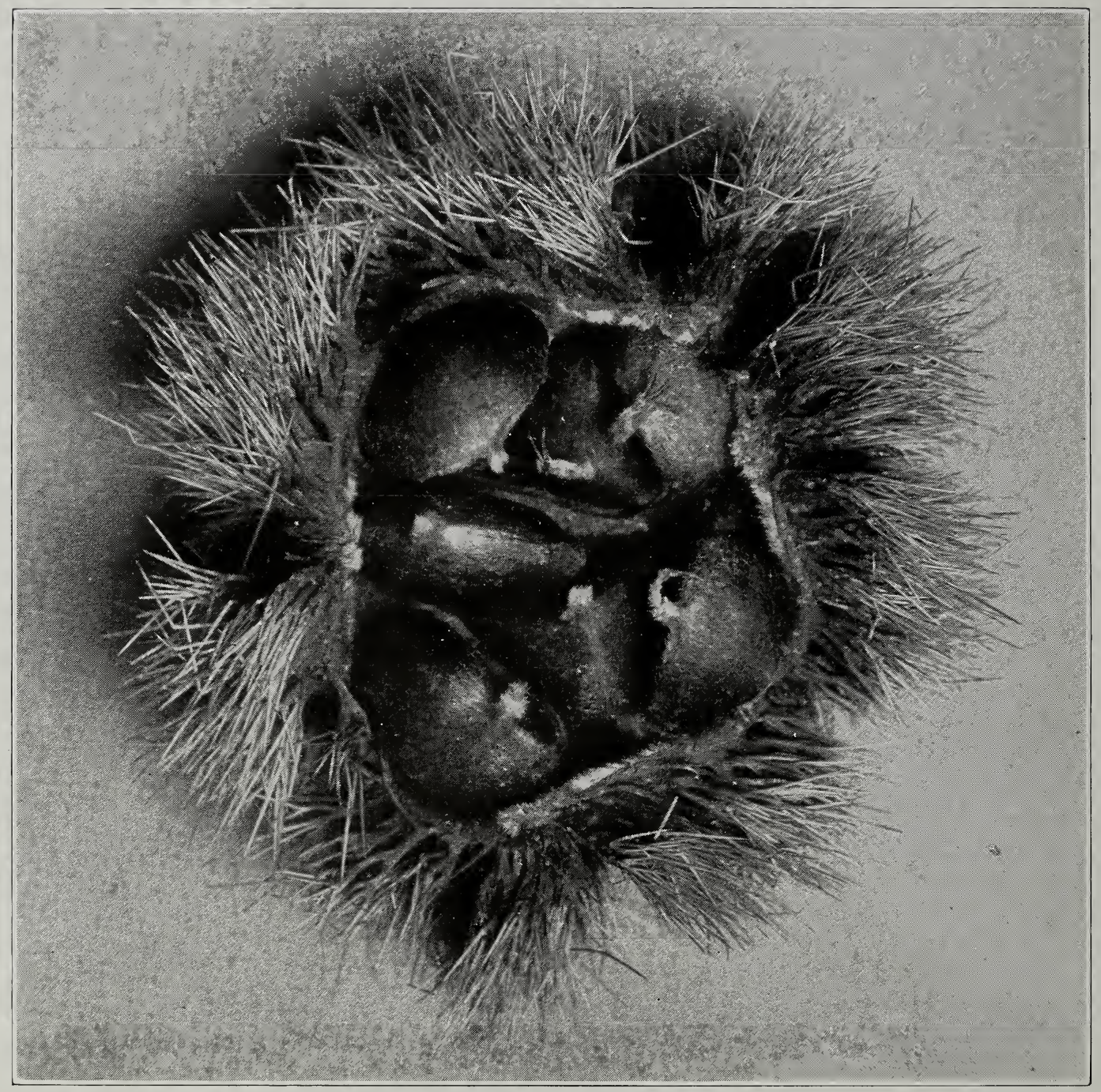

A BURR FROM ONE OF OUR THREE YEAR OLD PARAGON CHESTNUT TREES. 


\section{CHESTNUT.}

Chestnut culture in the United States, while still in its infancy, is older than that of the Pecan and it has been fully demonstrated that the Chestnut can be successfully grown in practically all the territory north of Alabama, and in some sections further south.

In the middle west the demand for high-grade Chestnuts has always been far in excess of the supply and to those who like this delicious nut and who desire a fine shade tree, which will produce bountifully of its treasure and supply shade long after the average purely shade tree is dead, we heartily recommend the Chestnut.

These trees will grow upon almost any soil and to those of you who have worn out, rocky hills, we strongly recommend putting same in Chestnut trees. Many of these trees bear in our Nursery at the age of two years.

The demand for Chestnuts invariably exceeds the supply.

Our Chestnut trees are absolutely free of blight.

We have in stock and thoroughly recommend the following varieties:

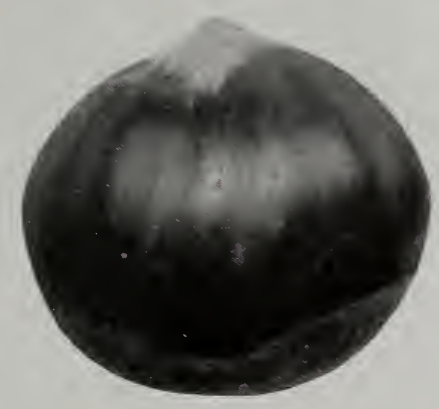

\section{PARAGON.}

Very large and sweet and probably the best known Chestnut in America.

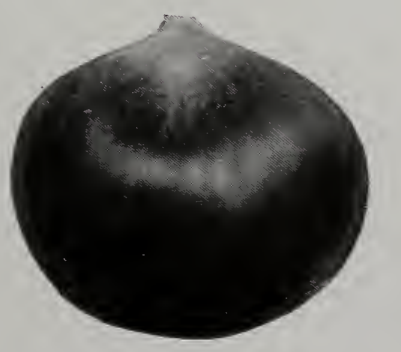

\section{BOONE.}

Contains Japanese strain and has a beautiful foliage. Nut rich and sweet. 

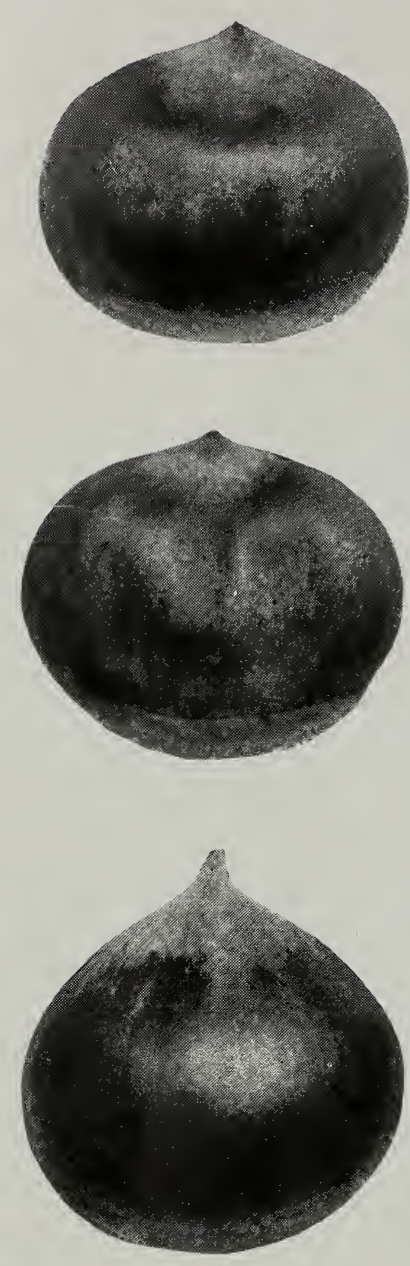

McFARLAND.

Contains crossed American strain. Nut sweet and tender.

\section{COOPER.}

A very fine tree. Nut plump and sweet.

\section{ROCHESTER.}

Probably originated in America and first offered by E. A. Riehl. Quality sweet and excellent.

\section{RUSH HYBRID CHINQUAPIN.}

Originated in America and thought to be a hybrid of the Bush Chinquapin and the American Sweet Chestnut. The nut is smaller than the Chestnut, but of better quality, in fact, many people claim it to be the sweetest and daintiest of all nuts. The nut is borne in large clusters. The tree is very productive, the foliage very dense and the tree makes a symmetrical and beautiful appearance upon the lawn.

For your large lawn, driveway or park, plant some of these Chestnuts and lend a stateliness, dignity and beauty thereto that cannot be surpassed.

We positively sell no seedlings of these Chestnuts. 


\section{ENGLISH (PERSIAN) WALNUTS.}

It is believed by many people that the English (Persian) Walnut is not grown in this country. This error has arisen principally because of the name. Many very old English Walnut trees are found in different parts of the United States and for some years the budding and grafting of these trees have been carried on by the leading nurserymen.

Many thousand trees that have been budded and grafted in California and several large English Walnut seedling orchards in New York State are producing immense crops and realizing excellent profits.

The trees are among the best known for shade purposes and there is a demand for the nuts far beyond the supply. They will bear from the fourth to the seventh year.

We have given much time and attention to the propagation of this nut in our Nursery and after thorough testing have come to the conclusion that the varieties of English Walnuts, which we will sell and recommend to our customers are those quoted here.

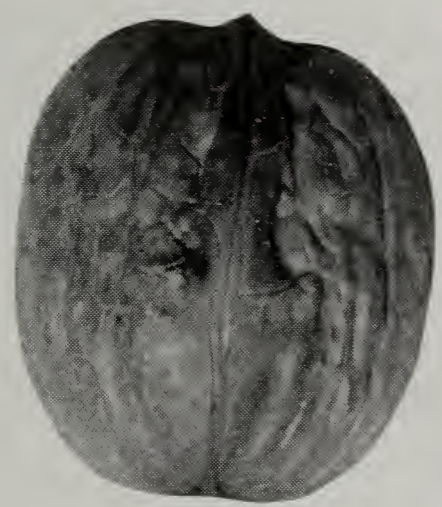

\section{MAYETTE.}

Originated in France. The nut is large, smooth and of very fine appearance. Probably the finest nut for market and invariably brings a good price. This and the following English Walnuts are hardy and the trees are vigorous in growth and very hand-

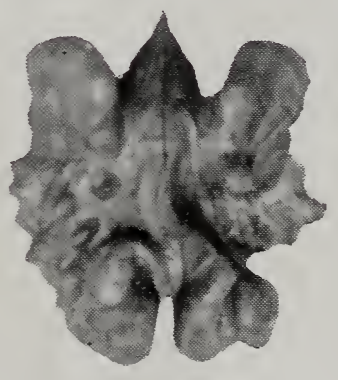
some.

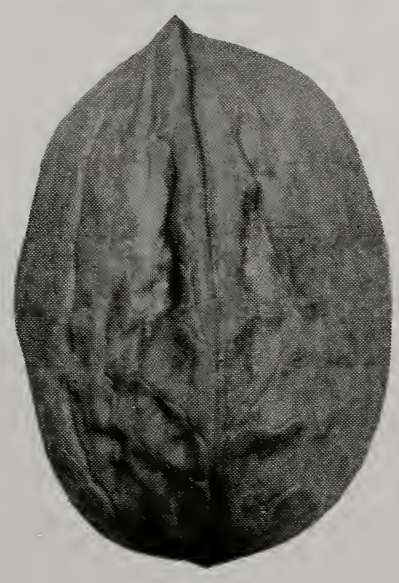

FRANQUETTE.

One of the best of the French strain. The nut is large and smooth and brings a good price.

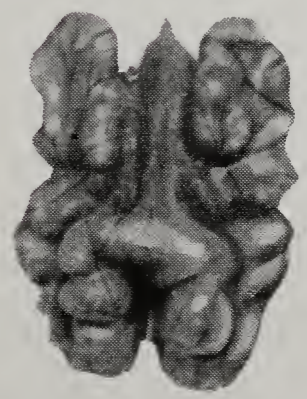




\section{HALL.}

Very hardy-annual bearer. Probably the largest English Walnut. Quality good.

\section{RUSH.}

Has good bearing record-Hardy. Comes into bearing the fourth or fifth year. Shell thin and quality good.

\section{HOLDEN.}

The shell is large, smooth and attractive. The kernel is plump and excellent flavor.
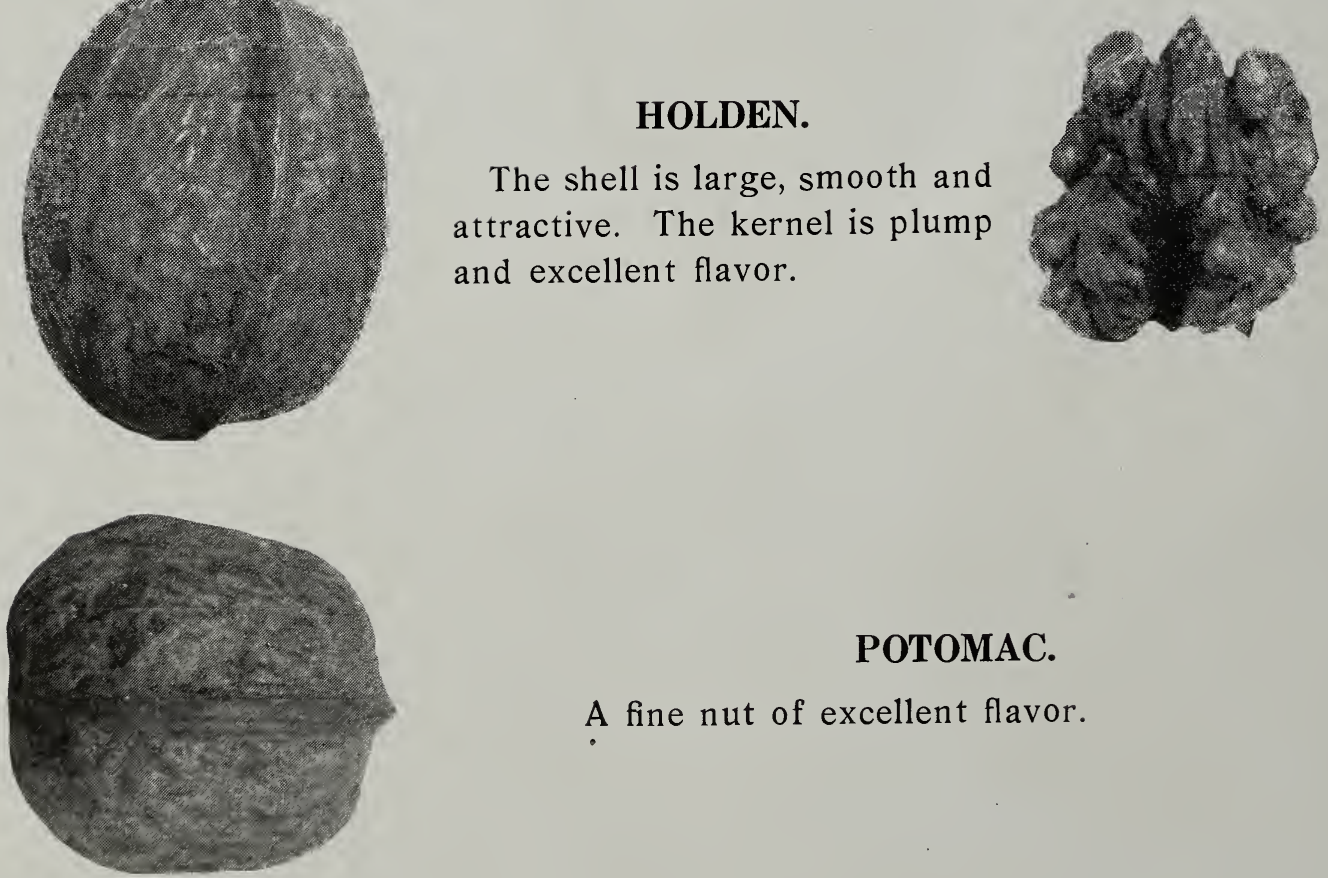

\section{POTOMAC.}

A fine nut of excellent flavor. 


\section{POMEROY.}

Of medium size. Kernel is full and of excellent quality.

\section{NEBO.}

One of the finest varieties. Nut is quite large and the kernel is full and of good quality.

We sell no English Walnut seedlings.

\section{BLACK WALNUT.}

For those who desire a Black Walnut, that tree of beautiful foliage and magnificent shade, and for those who love the flavor of this nut, we have bred the following strains:

The Miller.

The Ten-Eyck.

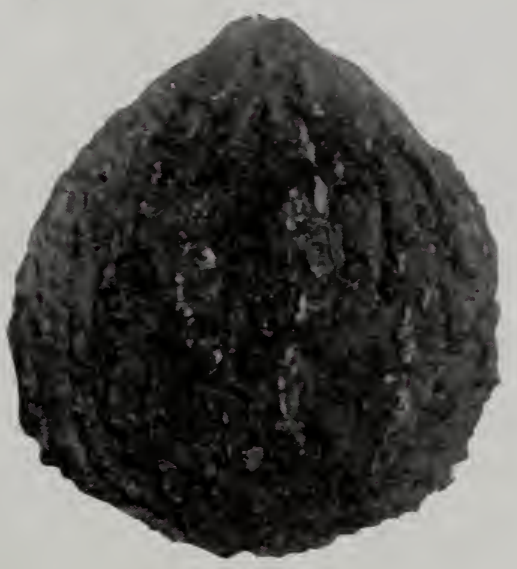

THE THOMAS.

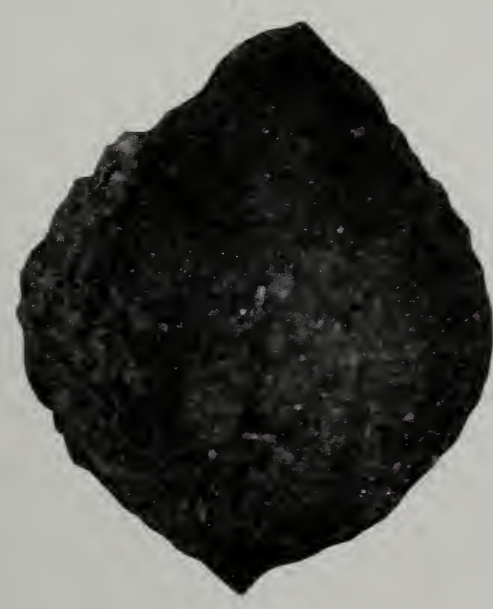

\section{THE STABLER.}

This is the best cracker known, but quality and foliage is no better than the other Black Walnuts above listed.

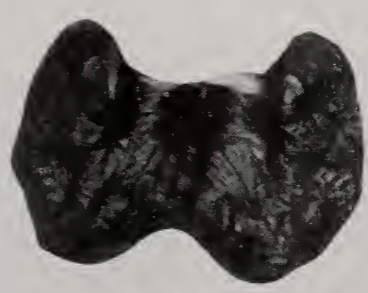




\section{JAPANESE WALNUT.}

Juglan's Cordiformis.

Juglan's Seiboldina.

These are choice varieties imported by us direct from Japan. Will withstand a very low temperature. Shell thicker than English Walnut and the kernel usually comes out whole and is of excellent quality. Trees grow with great vigor and usually bear when two or three years old.

\section{ALMOND.}

Hard Shell.

Many people will be surprised to see the Almond listed, but we have for sale the above Hard Shell. This tree is extremely hardy and very showy when in bloom. Will grow and bear very far north. The kernel is large and very sweet. Will produce in from three to four years.

\section{THE BUTTERNUT OR WHITE WALNUT.}

This lofty, magnificent tree is one of our finest native trees.

The tree grows rapidly and produces large, elongated nuts, with a rich, sweet, oily kernel which is very nutritious. Shell hard and brittle. The nut usually cracks out whole.

We have the pure strain and guarantee it true to name.

\section{HICKORIES.}

These trees are handsome and vigorous growers. The wood tough and white, of great strength and elasticity.

\section{The Kentucky Shellbark.}

Grafted or budded, kernel very rich and sweet, nut above average in size, very white and good cracker.

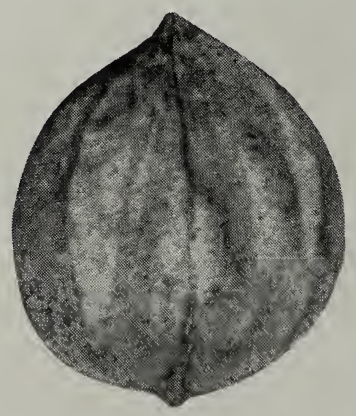




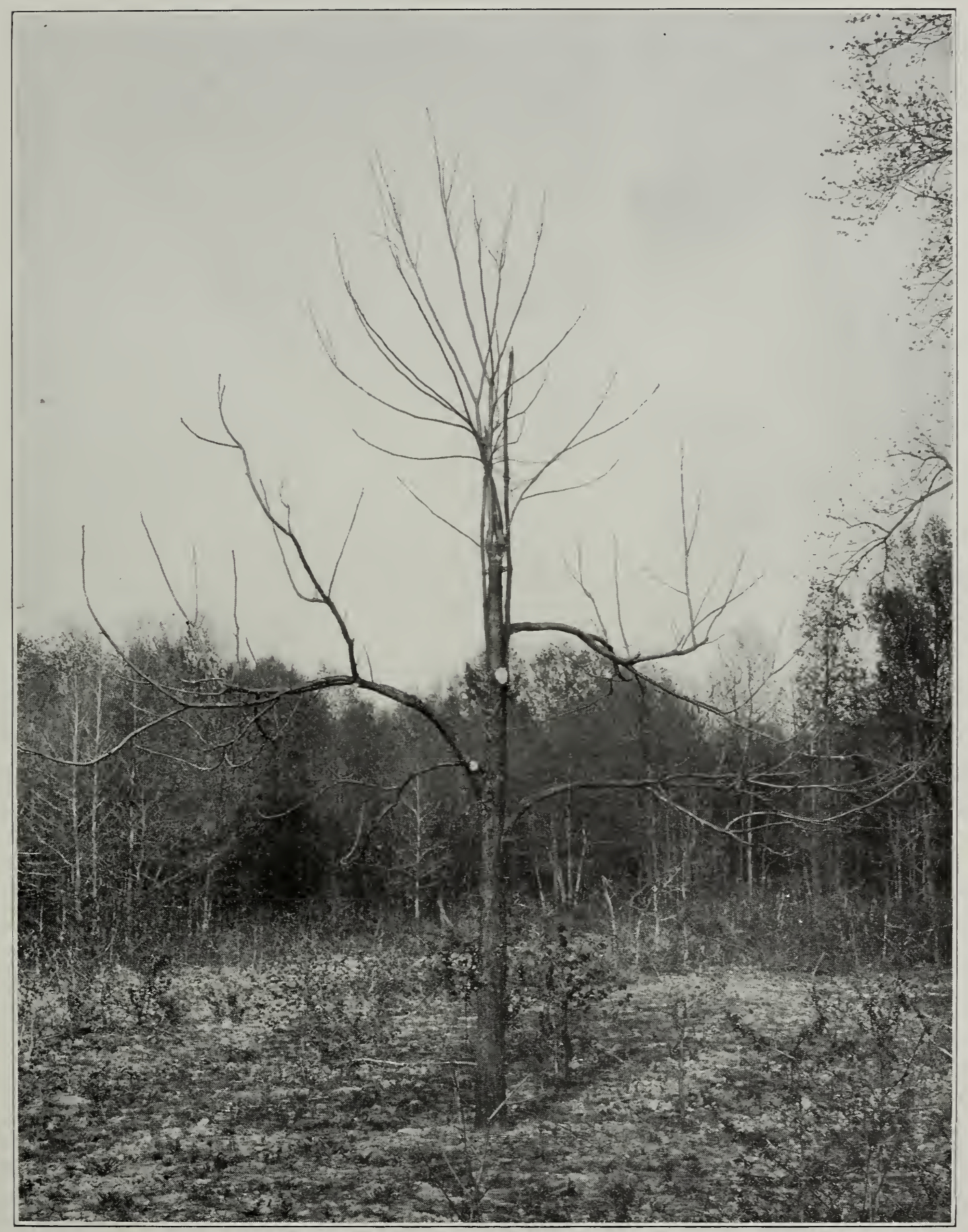

A NATIVE SEEDLING PECAN TOP-WORKED WITH ONE OF OUR IMPROVED VARIETIES OF PECANS. 


\section{TOP-WORKING.}

Briefly-"Top-Working" is the method employed to change the tops of fruit or nut trees, so that they will produce different or better fruit than did the old tree.

The importance to the owner of one or many inferior nut trees, of topworking them, as a means of changing them into speedy and bountiful producers of high-grade nuts, cannot be over-estimated.

Many seedling orchards scattered over the entire nut area, as well as wild trees, are being transformed in this manner.

Top-working, while comparatively new, has come to stay, as its advantages are manifold and its practicability and success are already assured.

Top-working may be done by one of two methods, namely budding or slipbarking and only an expert should attempt it.

A photograph of one of the many top-worked trees in our Nurseries is shown in this catalogue.

If you have any Black Walnut, White Walnut, or Japanese Walnut trees, they can be made to produce English Walnuts.

If you have a Hickory or inferior Pecan, a high-grade Pecan may be topworked thereon.

High-grade Chestnuts may be top-worked onto inferior Chestnut or Chestnut Oak trees, and the celebrated Rush Chinquapin may be top-worked onto an inferior Chestnut or Chestnut Oak.

We take pleasure in calling your attention to the fact that our Mr. McCoy is a pioneer in the top-working art (for art it really is), he having for many years top-worked our native wild nut trees, and to those who are interested, we will be pleased to give all the information at our command.

In top-working, we guarantee our work, and the bud wood or scion topworked on to the old tree, is guaranteed to be absolutely true to name.

\section{BUD-WOOD.}

We are prepared to furnish to selected patrons, bud-wood from any tree mentioned in this catalogue. 


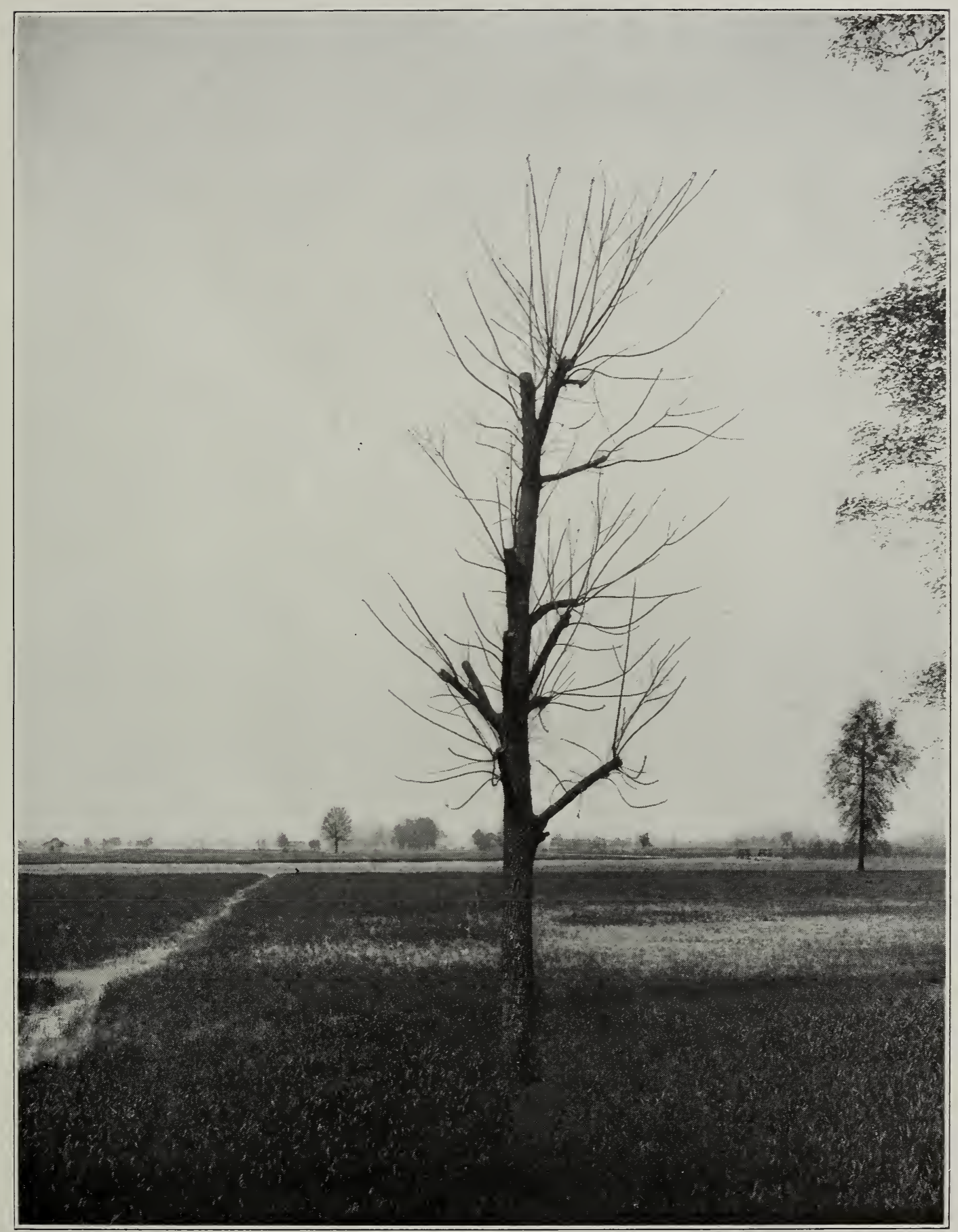

A NATIVE BLACK WALNUT CUT BACK READY TO BE TOP-WORKED BY BUDDING ENGLISH WALNUT SCIONS. 


\section{NUT CRACKS.}

The famous Butterick Pecan tree has not had a crop failure in sixty years. The tree is known to have been bearing since 1817. The smallest crop in sixty years was $31 / 2$ bushels, which occurred in an off year.

The demand for Pecans, English Walnuts and Chestnuts always exceeds the supply.

Our Pecan trees frequently begin to produce two years after being transplanted.

The Pecan, English Walnut and Chestnut trees have no superior as shade trees.

All our Mother Trees are very old and prolific.

In 1909 the census reports show that there were produced in the United States 9,890,769 pounds of Pecans, valued at $\$ 971,596.00$.

Pecan trees will frequently grow to over one hundred feet in height and many trees have a spread of 100 feet from tip to tip.

After a few years your trees will produce sufficient nuts to more than offset the original cost.

In ten to twelve years your Pecan tree should yield about five bushels; twenty trees to the acre will make your yearly crop of the value of $\$ 600.00$ per acre.

There are authentic records in Europe of an English Walnut tree yielding as much as 2,000 pounds per crop.

The Rural New Yorker says, "Nut growing is a business which is to be a great feature in future farming. $* * *$ A few men realize what is coming and are interesting themselves in the improved varieties of nuts-such as Hickories, Chestnuts and Pecans."

The American Cultivator says, "Fortunes are sure to be accumulated by growers of nut trees, who engage largely and intelligently in the business. $* * *$ No industry embodies to a greater degree the elements of safety, profit and permanence as an investment."

An acre planted in budded or grafted English Walnut trees should, at the age of ten years, conservatively produce over 1,000 pounds of nuts, making your acreage yield over $\$ 175.00$. And as the trees become older they will greatly increase their yield.

Last year the English Walnut crop from 228 seedling trees at North Avon, New York sold for more than $\$ 2,000.00$. Had these trees been budded or grafted the yield would have been $40 \%$ or more, greater. 
Average fuel value of English Walnuts and Pecans in comparison with other food products.

\section{FUEL VALUE OF EDIBLE PORTION.}

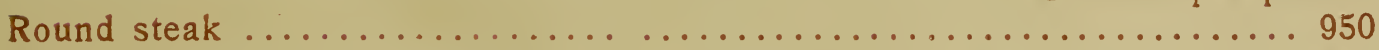

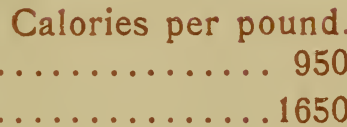

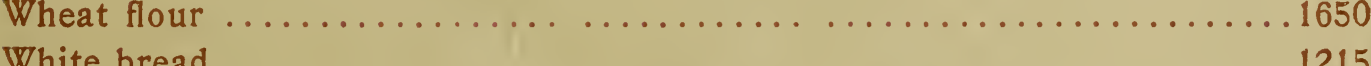

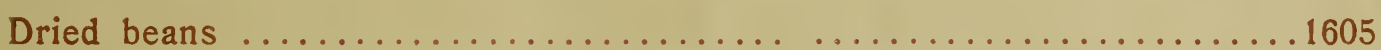

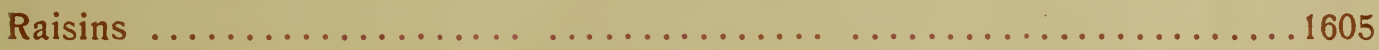

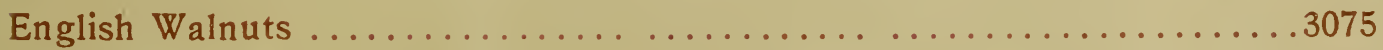

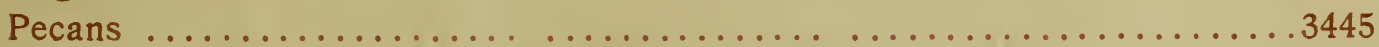

\section{ABOUT SEEDLING TREES.}

Some Nurseries will offer to sell you Pecan, Chestnut and English Walnut seedlings at much less than the budded or grafted stock. We have over 200,000 seedlings in our Nurseries, but absolutely refuse to sell them to the trade; the reason being that these seedlings so frequently come untrue to variety, and consequently we would have a dissatisfied customer. It is our aim and desire to keep in touch with each customer at all times and freely and willingly give him the benefit of the experience of our experts.

Shipping season on nut trees, fall, winter and early spring.

If you desire any information or advice in our line, we will be pleased to give you the benefit of our experience.

Address all orders and communications to

THE MCCOY NUT NURSERIES, Old State National Bank Building, Evansville, Indiana. 
